\title{
Two new species of the genus Trilacuna from Chongqing, China (Araneae, Oonopidae)
}

\author{
Yanfeng Tong', Xijin Guan', Shuqiang $\mathrm{Li}^{2}$ \\ I Life Science College, Shenyang Normal University, Shenyang 110034, China 2 Institute of Zoology, Chinese \\ Academy of Sciences, Beijing 100101, China \\ Corresponding author: Shuqiang Li (lisq@ioz.ac.cn)
}

Academic editor: Y. Marusik | Received 20 December 2017 | Accepted 28 May 2018 | Published 5 July 2018

http://zoobank.org/B9C65021-1C5E-4654-B4AB-9151212637F2

Citation: Tong Y, Guan X, Li S (2018) Two new species of the genus Trilacuna from Chongqing, China (Araneae, Oonopidae). ZooKeys 771: 41-56. https://doi.org/10.3897/zookeys.771.23158

\begin{abstract}
Two new species of the genus Trilacuna Tong $\& \mathrm{Li}, 2007$, T. simianshan Tong $\& \mathrm{Li}$, sp. n. and T. songyuae Tong \& Li, sp. n., are described from Simianshan Natural Reserve, Chongqing, China.
\end{abstract}

\section{Keywords}

Asia, copulatory organs, Gamasomorphinae, spider, taxonomy

\section{Introduction}

The spider genus Trilacuna was established by Tong and $\mathrm{Li}$ in 2007 to accommodate two new species, T. angularis Tong $\& \mathrm{Li}, 2007$ and T. rastrum Tong $\& \mathrm{Li}, 2007$, from Southwest China. Subsequently, additional species have been described from Thailand, Malaysia and Sumatra (Eichenberger and Kranz-Baltensperger 2011), Vietnam (Tong and Li 2013), the Himalayan region (Grismado et al. 2014), Iran (Malek-Hosseini et al. 2015), and Korea (Seo 2017). Currently, the genus Trilacuna comprises 20 species known from Asia (World Spider Catalog 2018).

This genus was originally diagnosed by the enlarged male palpal femora, the very complicated embolus-conductor complex, the branched endites in males and the notched labium (Tong and Li 2007). Grismado et al. (2014) re-diagnosed Trilacuna by 
the loss of the furrow connecting the posterior spiracles in males. However, as already discussed by Grismado et al. (2014) and Malek-Hosseini et al. (2015), some species, i.e., T. aenobarba (Brignoli, 1978), T. bangla Grismado \& Ramírez, 2014, T. hazara Grismado \& Ramírez, 2014 and T. qarzi Malek Hosseini \& Grismado, 2015, have a shallow groove connecting the spiracles in males; T. diabolica Kranz-Baltensperger, 2011 and T. werni Eichenberger, 2011 have a well-developed furrow connecting the spiracles in males. So far, all known species of Trilacuna have a long postepigastric scutum in the females. This character is useful to distinguish Trilacuna from the other genera in the "Dysderoides complex" (Grismado et al. 2014; Tong and Li 2015).

In this paper two new Trilacuna species, T. simianshan Tong \& Li, sp. n. and T. songyuae Tong \& Li, sp. n., collected in the Simianshan Mountains, are described and illustrated.

\section{Materials and methods}

The specimens were examined using a Leica M205C stereomicroscope. Details were studied under an Olympus BX51 compound microscope. Photos were made with a Canon EOS 550D zoom digital camera (18 megapixels) mounted on an Olympus BX51 compound microscope. Vulvae were cleared in lactic acid. For scanning electron microscopy (SEM), specimens were air-dried and uncoated. Pictures were taken with a Hitachi TM3030. All measurements were taken using an Olympus BX51 compound microscope and are in millimeters.

The following abbreviations are used in the text and figures:

$\begin{array}{llll}\text { ALE } & \text { anterior lateral eyes; } & \text { pe } & \text { posterior extension; } \\ \text { apo } & \text { apodemes; } & \text { PLE } & \text { posterior lateral eyes; } \\ \text { blo } & \text { broom-like outgrowth; } & \text { PME } & \text { posterior median eyes; } \\ \text { boc } & \text { booklung covers; } & \text { psc } & \text { paddle-like sclerite; } \\ \text { cll } & \text { cluster of long line-like structure; } & \text { psp } & \text { posterior spiracles; } \\ \text { cp } & \text { circular projection; } & \text { rlo } & \text { ribbon-like outgrowth; } \\ \text { css } & \text { cone-shaped structure; } & \text { rp } & \text { rectangular projection; } \\ \text { dd } & \text { dark dot; } & \mathbf{s d b} & \text { slightly distal branch; } \\ \text { dk } & \text { dark knob; } & \mathbf{s l h} & \text { small hole; } \\ \text { ehb } & \text { elevated hair base; } & \mathbf{s l s} & \text { slender line-like structure; } \\ \text { fo } & \text { fold; } & \mathbf{s p} & \text { sperm pore; } \\ \mathbf{l d i} & \text { labium deep incision; } & \mathbf{s p r} & \text { small projection; } \\ \text { mp } & \text { membranous projection; } & \mathbf{s p s} & \text { spear-like setae; } \\ \text { nls } & \text { numerous, long setae; } & \mathbf{s s o} & \text { sector-shaped outgrowth; } \\ \mathbf{o g r 1} & \text { outgrowth 1; } & \mathbf{s s p} & \text { sickle-shaped protuberance; } \\ \mathbf{\text { ogr2 }} & \text { outgrowth 2; } & \text { tss } & \text { two long, strong setae. }\end{array}$

Type material is deposited in Shenyang Normal University (SYNU) and the Institute of Zoology, Chinese Academy of Sciences in Beijing (IZCAS). 


\section{Taxonomy}

Trilacuna Tong \& Li, 2007

Type species. Trilacuna rastrum Tong \& Li, 2007.

\section{Trilacuna simianshan Tong \& Li, sp. $\mathrm{n}$.}

http://zoobank.org/899E9966-88FD-4512-AE01-1C74A42ECB3F

Figs $1-5$

Type material. Holotype ${ }^{\lambda}$ (SYNU-99), China, Chongqing Municipality, Jiangjin Dist., Simianshan Natural Reserve, Dawopu, 28³5'14.628"N, 106²2'44.790"E, 1000 m, 20.X.2014, leg. Y. Tong. Paratypes: 1 ก, 2 + (SYNU-99), same data as

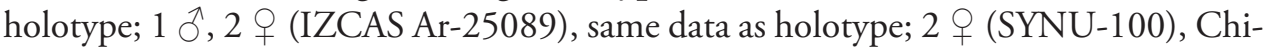
na, Chongqing Municipality, Jiangjin Dist., Simianshan Natural Reserve, Dawopu, $28^{\circ} 34^{\prime} 43.956 " \mathrm{~N}, 106^{\circ} 21^{\prime} 2.424^{\prime \prime E}, 28 \mathrm{~m}, 20 . X .2014$, leg. Y. Tong.

Etymology. The specific name is a noun in apposition taken from the type locality.

Diagnosis. This new species is similar to T. rastrum and can be distinguished by two long outgrowths of the embolus system and the long cone-shaped structure in females $v$ s. the embolus system with a short ribbon-like outgrowth and a rake-shaped protuberance, and a simple stick-shaped sclerite centrally on the female genitalia of $T$. rastrum (see Tong and Li 2007: figs 6-10).

Description. Male. Body yellow-brown, chelicerae and sternum lighter, legs yellow. Habitus as in Fig. 1A-C. Body length 2.21; carapace 1.13 long, 0.86 wide; abdomen 1.16 long, 0.75 wide. Carapace sides granulate; lateral margin rebordered, with a row of short, fine hairs and small blunt denticles. Six eyes, well developed, arranged in a compact group; ALE, PME subequal, larger than PLE; ALE-PLE separated by less than ALE radius, PME touching each other; posterior row recurved from above, procurved from front (Fig. 1D, G). Clypeus sinuous in frontal view, anterior lateral eyes separated from edge of carapace by about 2.0 times their diameter, with needle-like setae. Mouthparts: chelicerae straight, proximal region with one hair with elevated hair base (ehb); labium rectangular, anterior margin deeply incised (ldi) (Fig. 1E); endites slender, distally branched (sdb) (Fig. 1E). Sternum with radial furrows between coxae I-II, II-III, III-IV; surface strongly rugose on radial furrows and middle area; setae sparse, light, needle-like, evenly scattered (Fig. 1E). Abdomen: booklung covers large, ovoid, surface smooth (Fig. 2B). Dorsal scutum not fused to epigastric scutum. Apodemes present, posterior spiracles connected by a shallow groove (Fig. 2A). Leg spination (all spines longer than segment width): legs I-II: tibia: v2-2-2-2-0, metatarsus: v2-2-0. Trichobothria: tibia: each with three; metatarsus: each with one.

Genitalia. Epigastric region with sperm pore (sp) small, oval, rebordered, situated between anterior spiracles; with a small hole (slh) between the posterior spiracles 


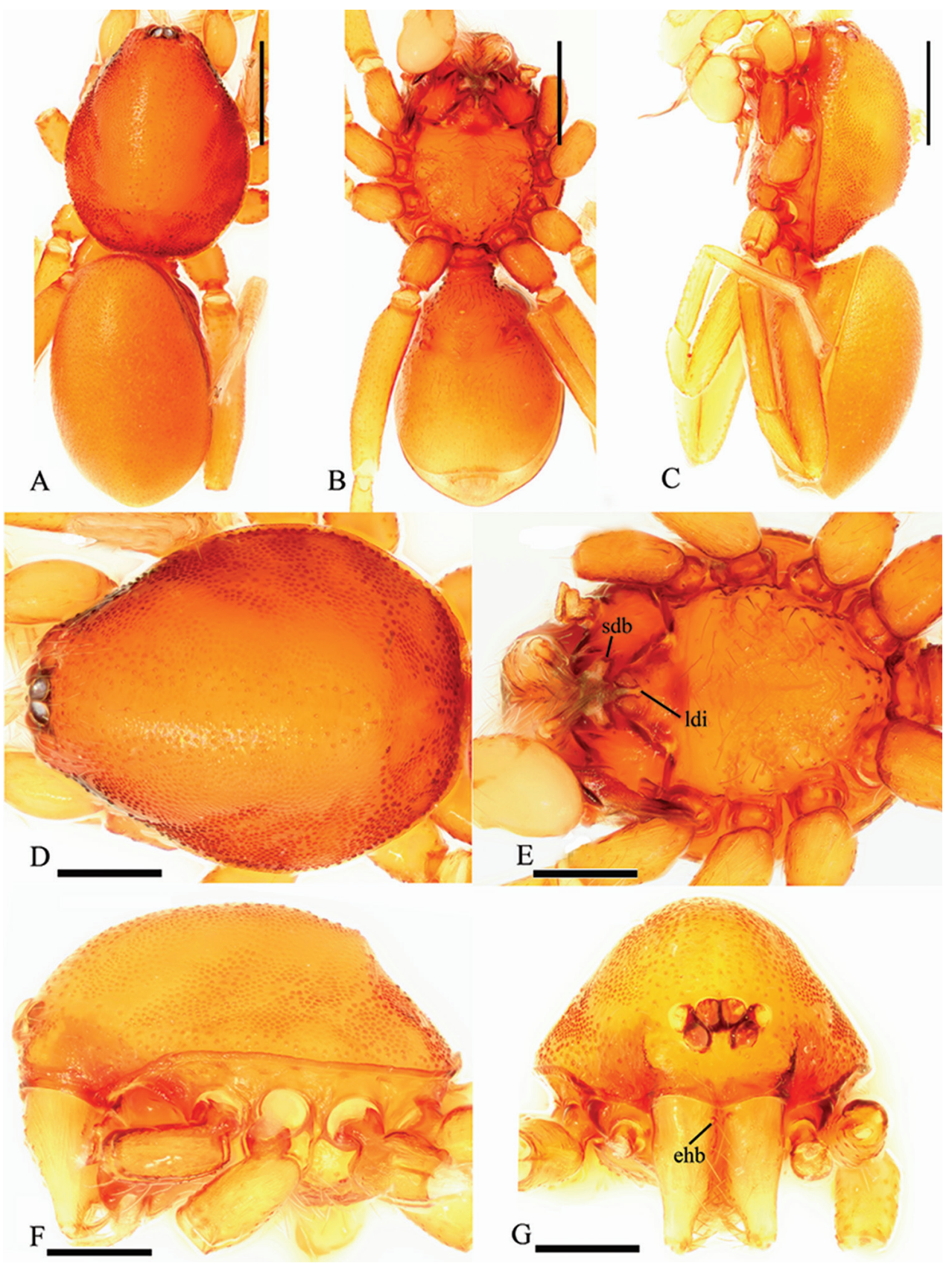

Figure I. Trilacuna simianshan sp. n., male. A habitus, dorsal view B habitus, ventral view $\mathbf{C}$ habitus, lateral view $\mathbf{D}$ prosoma, dorsal view $\mathbf{E}$ prosoma, ventral view $\mathbf{F}$ prosoma, lateral view $\mathbf{G}$ prosoma, anterior view. Abbreviations: ehb = elevated hair base; ldi = labium deep incision; $\mathrm{sdb}=$ slightly distal branch. Scale bars: $0.2 \mathrm{~mm}(\mathbf{A}-\mathbf{C}) ; 0.1 \mathrm{~mm}(\mathbf{D}-\mathbf{G})$. 


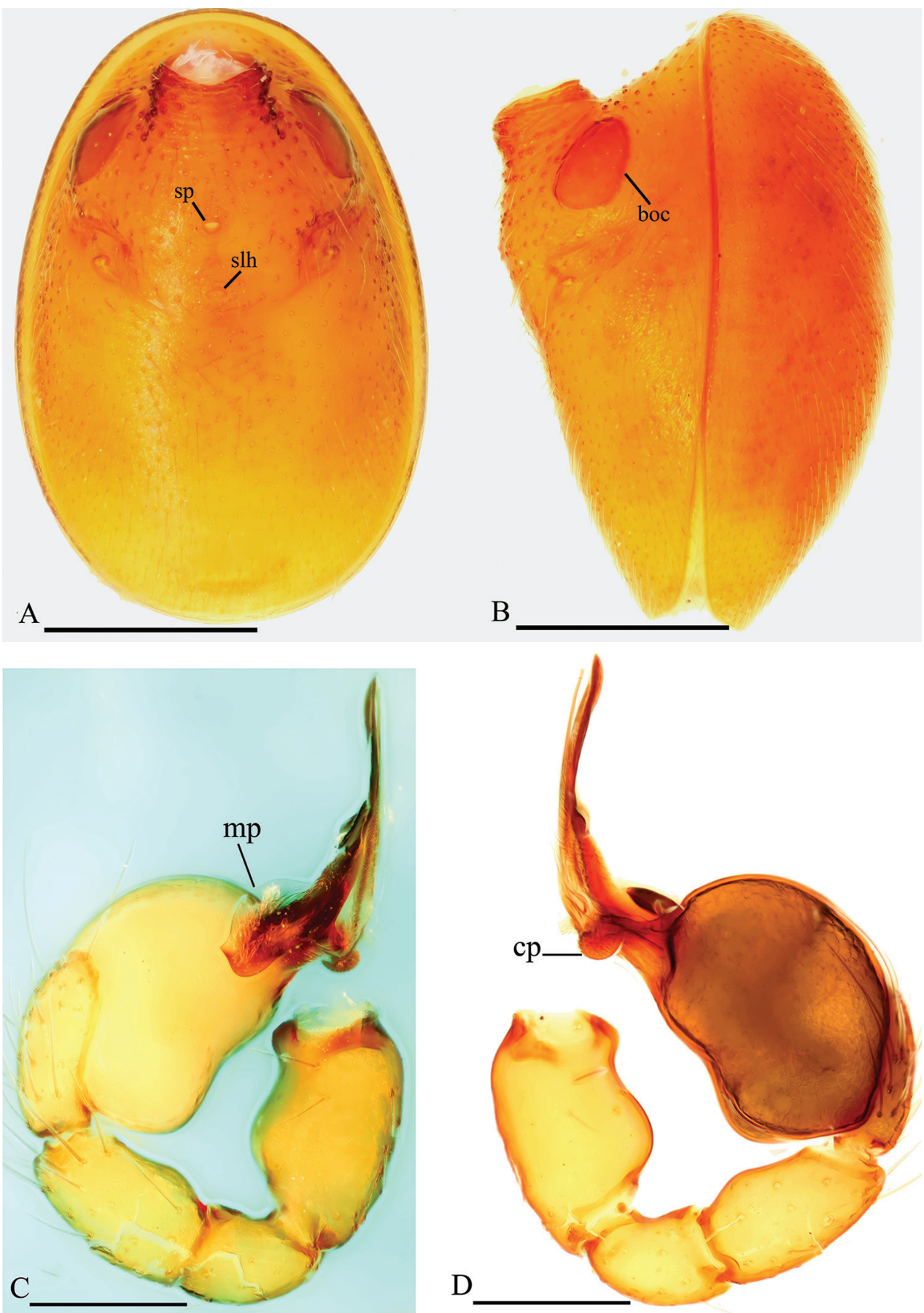

Figure 2. Trilacuna simianshan sp. n., male. A abdomen, ventral view $\mathbf{B}$ abdomen, lateral view $\mathbf{C}$ left palp, prolateral view $\mathbf{D}$ left palp, retrolateral view. Abbreviations: boc = booklung covers; $\mathrm{cp}=$ circular projection; $\mathrm{mp}=$ membranous projection; $\mathrm{slh}=$ small hole; $\mathrm{sp}=$ sperm pore. Scale bars: $0.2 \mathrm{~mm}$. 

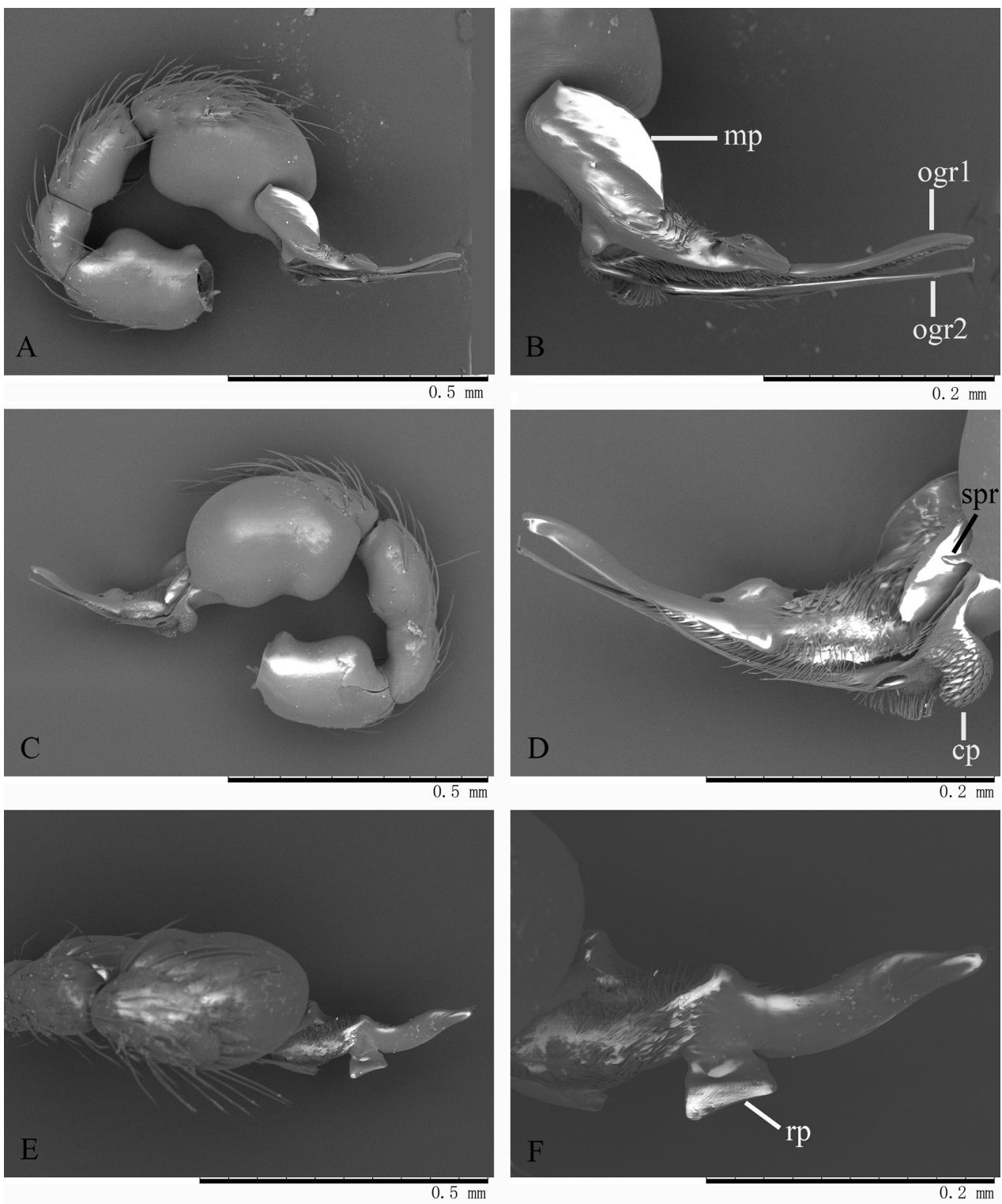

Figure 3. Trilacuna simianshan sp. n., male, SEM. A left palp, prolateral view B embolus system, prolateral view $\mathbf{C}$ left palp, retrolateral view $\mathbf{D}$ embolus system, retrolateral view $\mathbf{E}$ left palp, dorsal view $\mathbf{F}$ embolus system, dorsal view. Abbreviations: $\mathrm{cp}=$ circular projection; $\mathrm{mp}=$ membranous projection; $\operatorname{ogr} 1=$ outgrowth $1 ; \operatorname{ogr} 2=$ outgrowth $2 ; \mathrm{rp}=$ rectangular projection; $\mathrm{spr}=$ small projection .

(Fig. 2A). Palp (Figs 2C, D, 3): orange. 0.46 long $(0.15,0.08,0.11,0.12)$. Femur strongly swollen (width/length $=0.09 / 0.15$ ) (Fig. 2C, D). Bulb oval, stout, tapering apically. Embolus system (Fig. 3B, D, F) complex, with two long, strongly curved outgrowths (ogr1 and ogr2); the surface of the embolus system bearing numerous 

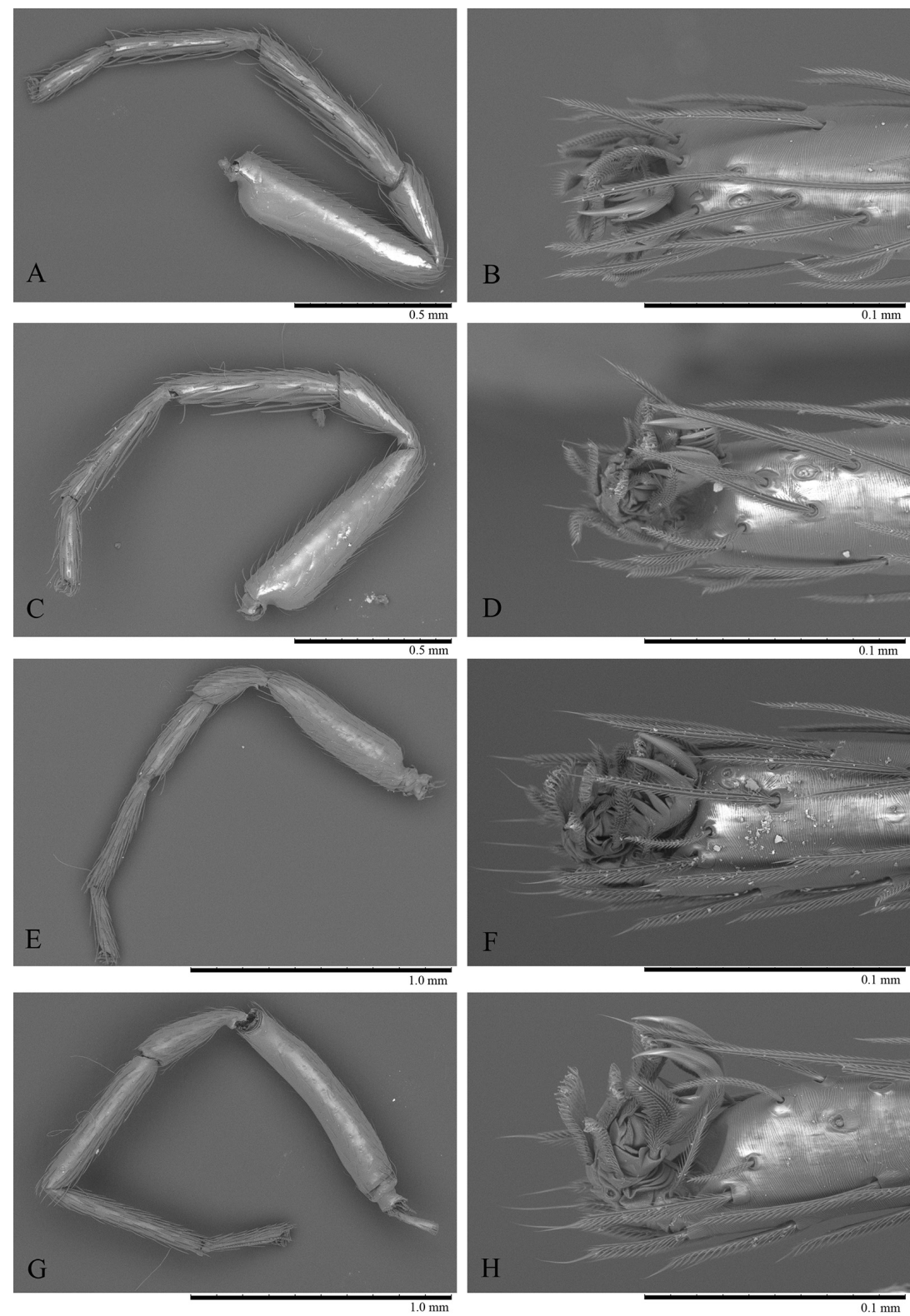

Figure 4. Trilacuna simianshan sp. n., female, right legs, SEM. A leg I, prolateral view B tarsus I, dorsal view $\mathbf{C}$ leg II, prolateral view $\mathbf{D}$ tarsus II, dorsal view $\mathbf{E}$ leg III, prolateral view $\mathbf{F}$ tarsus III, dorsal view $\mathbf{G}$ leg IV, prolateral view $\mathbf{H}$ tarsus IV, prolateral view.

small "papillae". The base of the embolus system with a wing-like, membranous projection (mp) in prolateral view and a circular projection (cp) covered with scales in retrolateral view; middle part of the embolus system with a rectangular projection (rp) in dorsal view. 


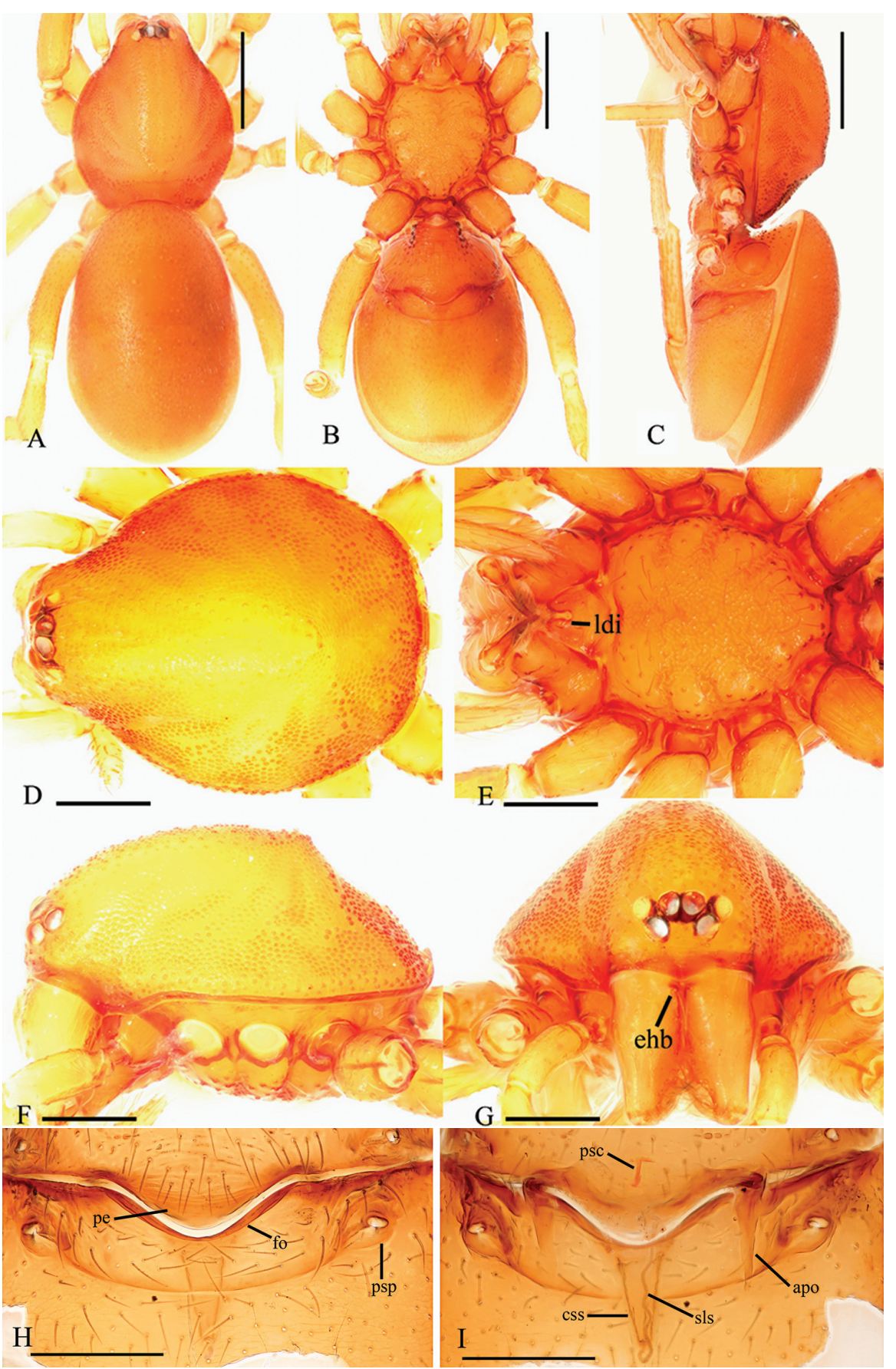

Figure 5. Trilacuna simianshan sp. n., female. A, B, C habitus, dorsal, ventral and lateral views $\mathbf{D}, \mathbf{E}, \mathbf{F}, \mathbf{G}$ prosoma, dorsal, ventral, lateral and anterior views $\mathbf{H , ~ I ~ g e n i t a l i a , ~ v e n t r a l ~ a n d ~ d o r s a l ~ v i e w s . ~ A b - ~}$ breviations: apo $=$ apodemes; $\operatorname{css}=$ cone-shaped structure; $\mathrm{ehb}=$ elevated hair base; fo = fold; ldi = labium deep incision; $\mathrm{pe}=$ posterior extension; $\mathrm{psc}=$ paddle-like sclerite; $\mathrm{psp}=$ posterior spiracles; $\mathrm{sls}=$ slender line-like structure. Scale bars: $0.2 \mathrm{~mm}(\mathbf{A}-\mathbf{C}) ; 0.1 \mathrm{~mm}(\mathbf{D}-\mathbf{I})$. 
Female. As in male except as noted. Slightly larger than male. Body length 2.28; carapace 0.99 long, 0.85 wide; abdomen 1.36 long, 0.89 wide. Postepigastric scutum long. Posterior spiracles connected by groove (Fig. 5B).

Female genitalia. Ventral view (Fig. 5H): Middle part of posterior margin of epigastric scutum much extended posteriorly (pe); surface without external features. Dorsal view (Fig. 5I): with a very long, nearly cone-shaped structure (css), at the posterior end of the cone-shaped structure is a slender line-like structure (sls) originating and extending anteriorly. Transverse bars with two relatively long, lateral apodemes.

Distribution. China (Chongqing).

\section{Trilacuna songyuae Tong $\& \mathrm{Li}$, sp. $\mathrm{n}$.}

http://zoobank.org/737A9BE2-8B18-4FA6-AB7E-D31F25495E0F

Figs 6-10

Type material. Holotype ${ }^{\lambda}$, (SYNU-101), China, Chongqing Municipality, Jiangjin Dist., Simianshan Natural Reserve, Dawopu, 28³4'43.956"N, 106²1'2.424"E, 28 m, 20.X.2014, leg. S. Lyu and Y. Tong. Paratypes: 2 ${ }^{\lambda}, 2$ + (SYNU-101), same data as holotype; $5 \hat{\partial}, 4$ q (SYNU-102), same data as holotype; $7 \hat{\partial}, 5$ + (IZCAS Ar-25088), China, Chongqing Municipality, Jiangjin Dist., Simianshan Natural Reserve, Dawopu, 283' $14.628^{\prime \prime N}, 106^{\circ} 22^{\prime} 44.790^{\prime E}, 1000$ m, 20.X.2014, leg. S. Lyu and Y. Tong.

Other material studied. $7 \hat{O}, 1$ (SYNU-103), same data as holotype; $8 \hat{O}, 2$ q (SYNU-105), China, Chongqing Municipality, Jiangjin Dist., Simianshan Natural Reserve, Dawopu, 28³5'14.628"N, 106²1'44.790"E, 1000 m, 20. X. 2014, leg. S. Lyu and Y. Tong.

Etymology. The specific name is after Miss Songyu Lyu (吕松宇), one of the collectors of this species.

Diagnosis. The new species is similar to T. hansanensis Seo, 2017. Both species have an elevated ridge on the posterior part of the male sternum, but can be distinguished by the long oval bulb, the very long setae (nls) on the prolateral surface of the male palpal tibiae and the two small, spear-like setae (sps) on the basal part of the prolateral surface of male palpal cymbium. Trilacuna hansanensis has a pear-shaped bulbus, and there are no special setae on the male palpal tibia or cymbium (see Seo 2017: figs 1A-K).

Description. Male. Body yellow-brown, chelicerae and sternum lighter, legs yellow. Habitus as in Fig. 6A-C. Body length 1.87; carapace 0.86 long, 0.73 wide; abdomen 0.97 long, 0.71 wide. Carapace sides granulate; lateral margin rebordered, with a row of short, fine hairs and small, blunt denticles. Eyes six, well developed, arranged in a compact group; ALE largest, PLE smallest; ALE-PLE separated by less than ALE radius, PME touching each other; posterior row recurved from above, procurved from front (Fig. 6D, G). Clypeus sinuous in frontal view, anterior lateral eyes separated from edge of carapace by about 2.0 times their diameter, with needle-like setae. Mouth- 


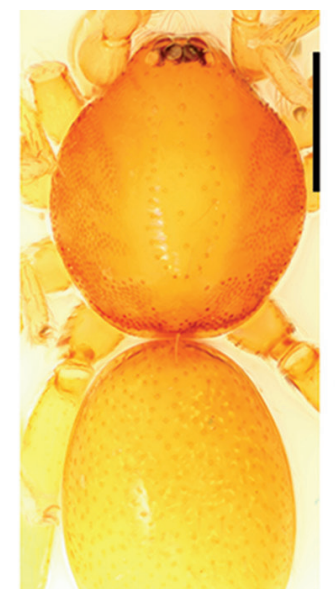

A
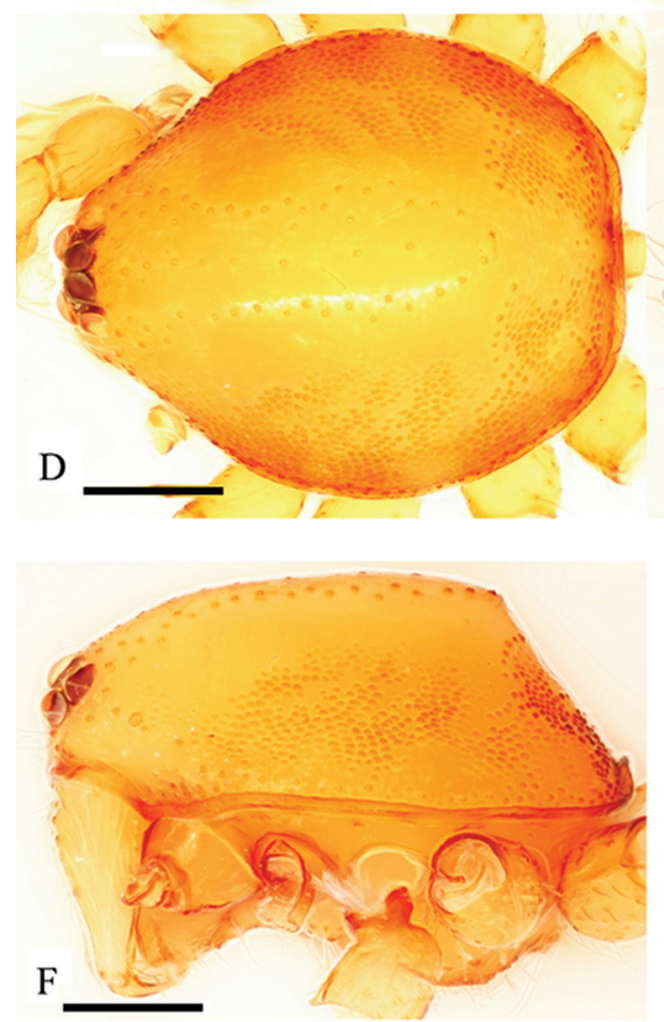

B
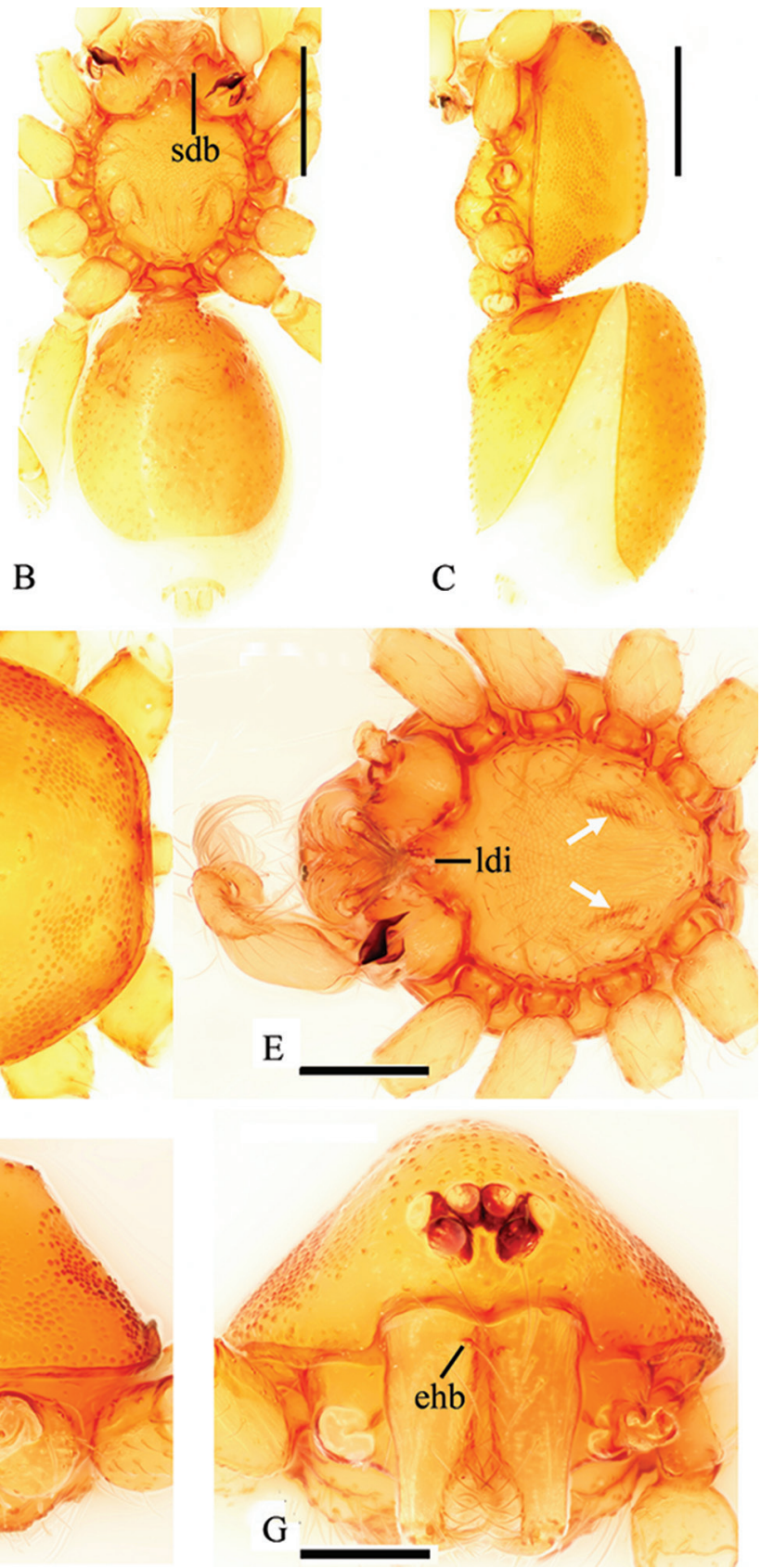

Figure 6. Trilacuna songyuae sp. n., male. A habitus, dorsal view B habitus, ventral view $\mathbf{C}$ habitus, lateral view $\mathbf{D}$ prosoma, dorsal view $\mathbf{E}$ prosoma, ventral view, white arrow shows the ridges, with a row of setae $\mathbf{F}$ prosoma, lateral view $\mathbf{G}$ prosoma, anterior view. Abbreviations: ehb = elevated hair base; ldi = labium deep incision; $\mathrm{sdb}=$ slightly distal branch. Scale bars: $0.2 \mathrm{~mm}(\mathbf{A}-\mathbf{C}) ; 0.1 \mathrm{~mm}(\mathbf{D}-\mathbf{G})$. 

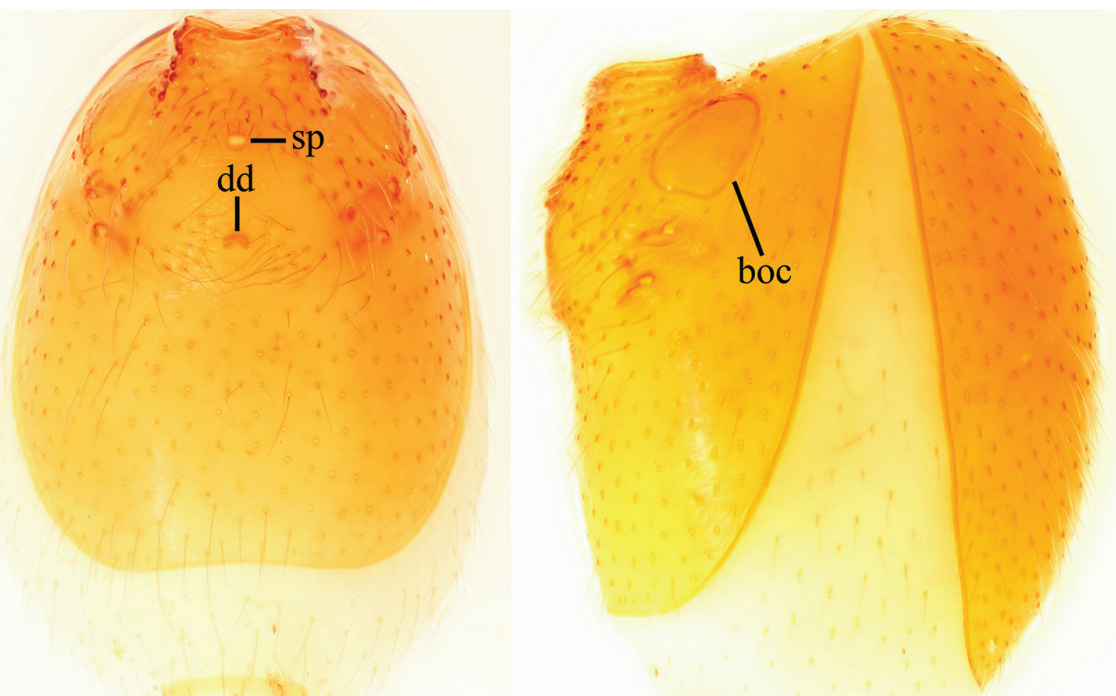

A

B
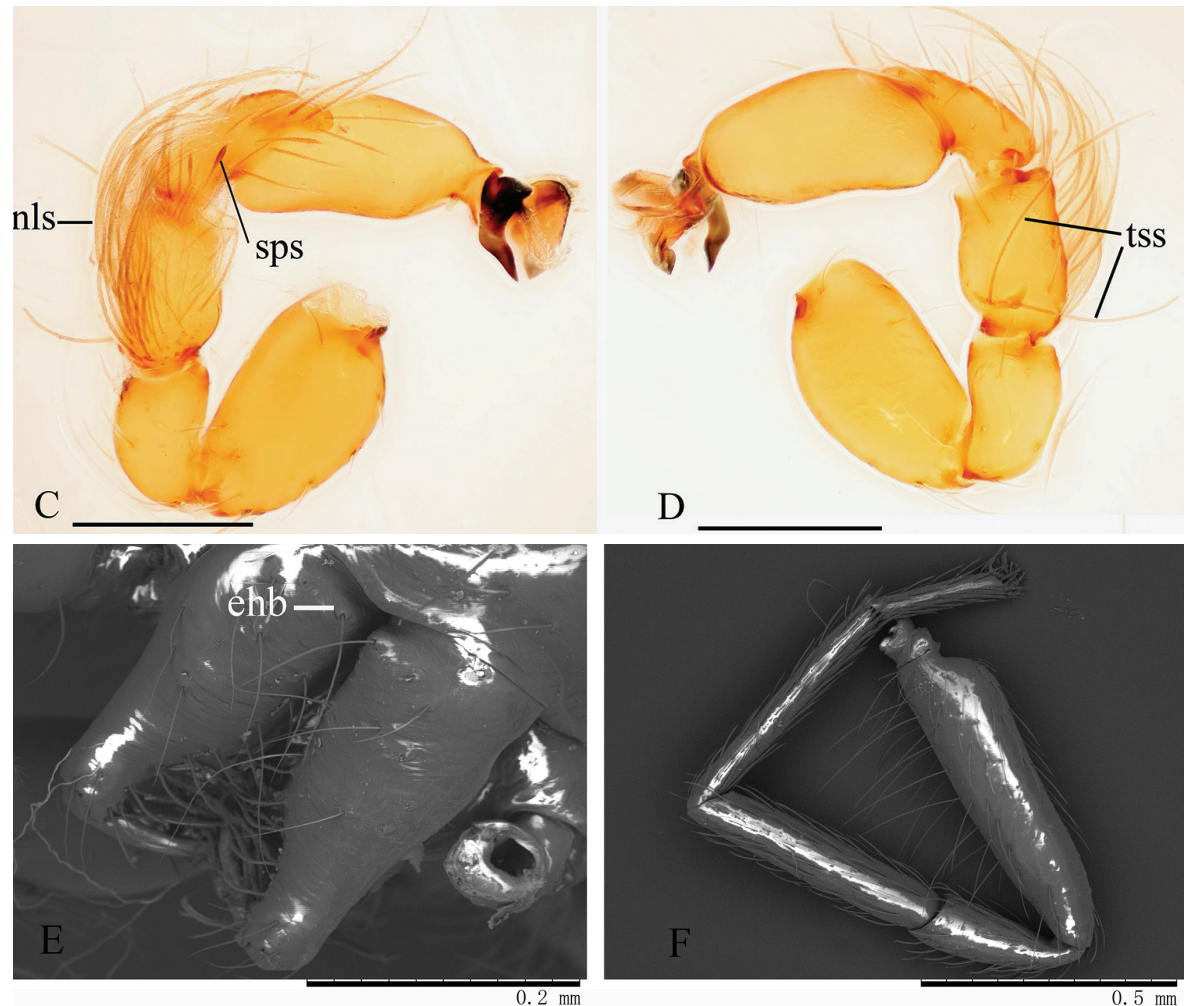

Figure 7. Trilacuna songyuae sp. n., male. A abdomen, ventral view $\mathbf{B}$ abdomen, lateral view $\mathbf{C}$ left palp, prolateral view $\mathbf{D}$ left palp, retrolateral view $\mathbf{E}$ chelicerae, oblique, anterior view $\mathbf{F}$ left leg IV, prolateral view. Abbreviations: boc = booklung covers; $\mathrm{dd}=\mathrm{dark}$ dot; $\mathrm{ehb}=$ elevated hair base; $\mathrm{nls}=$ numerous, long setae; $\mathrm{sp}$ = sperm pore; sps = spear-like setae; tss = two long, strong setae. Scale bars: $0.1 \mathrm{~mm}(\mathbf{A}-\mathbf{D})$. 

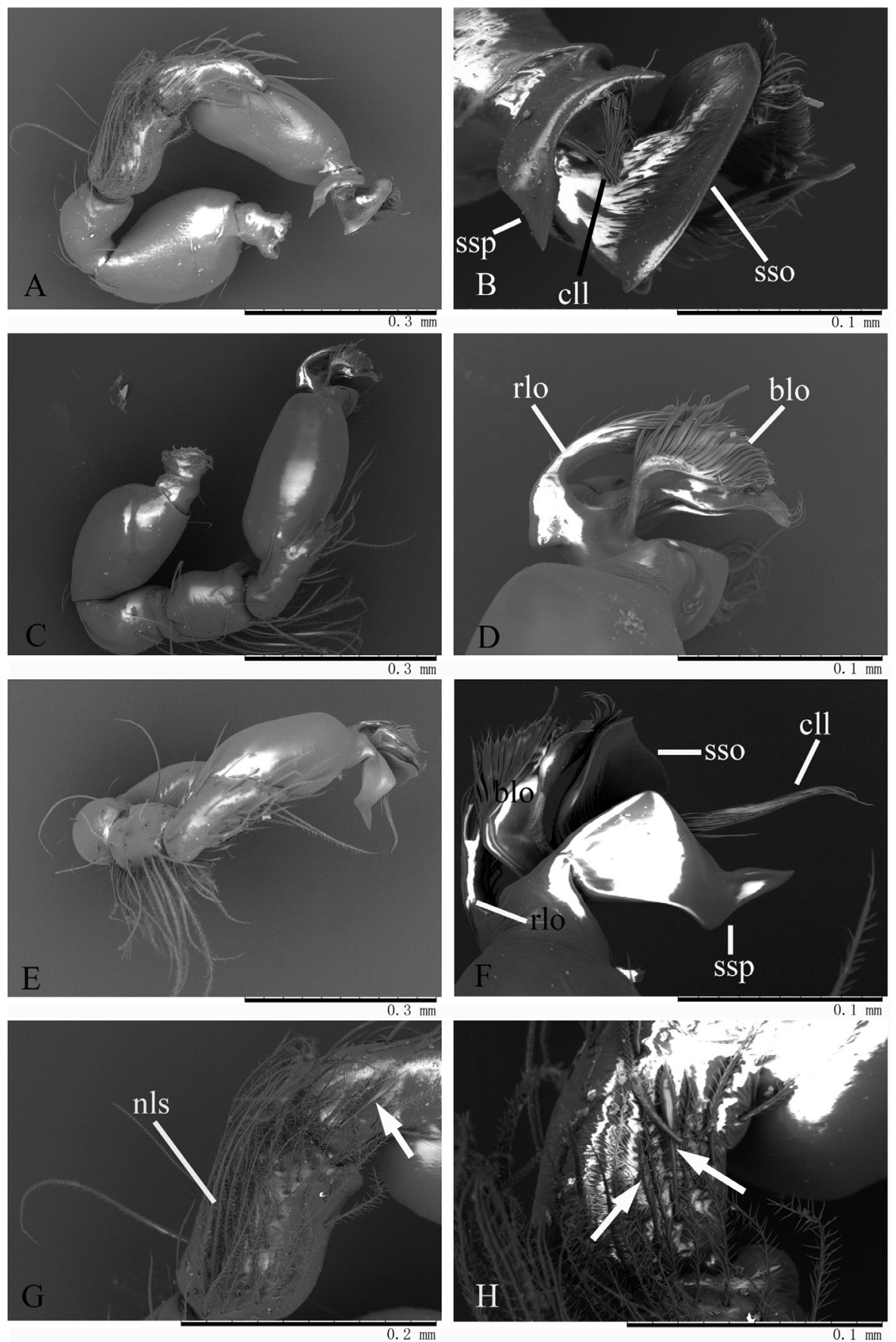

Figure 8. Trilacuna songyuae sp. n., male, SEM. A left palp, prolateral view $\mathbf{B}$ embolus system, prolateral view $\mathbf{C}$ left palp, retrolateral view $\mathbf{D}$ embolus system, retrolateral view $\mathbf{E}$ left palp, dorsal view $\mathbf{F}$ embolus system, dorsal view $\mathbf{G}$ tibia and cymbium, prolateral view $\mathbf{H}$ same, details, white arrow shows the spear-like setae. Abbreviations: blo = broom-like outgrowth; $\mathrm{cll}=$ cluster of long line-like structure; $\mathrm{nl}$ = numerous, long setae; rlo = ribbon-like outgrowth; sso = sector-shaped outgrowth; ssp = sickle-shaped protuberance. 

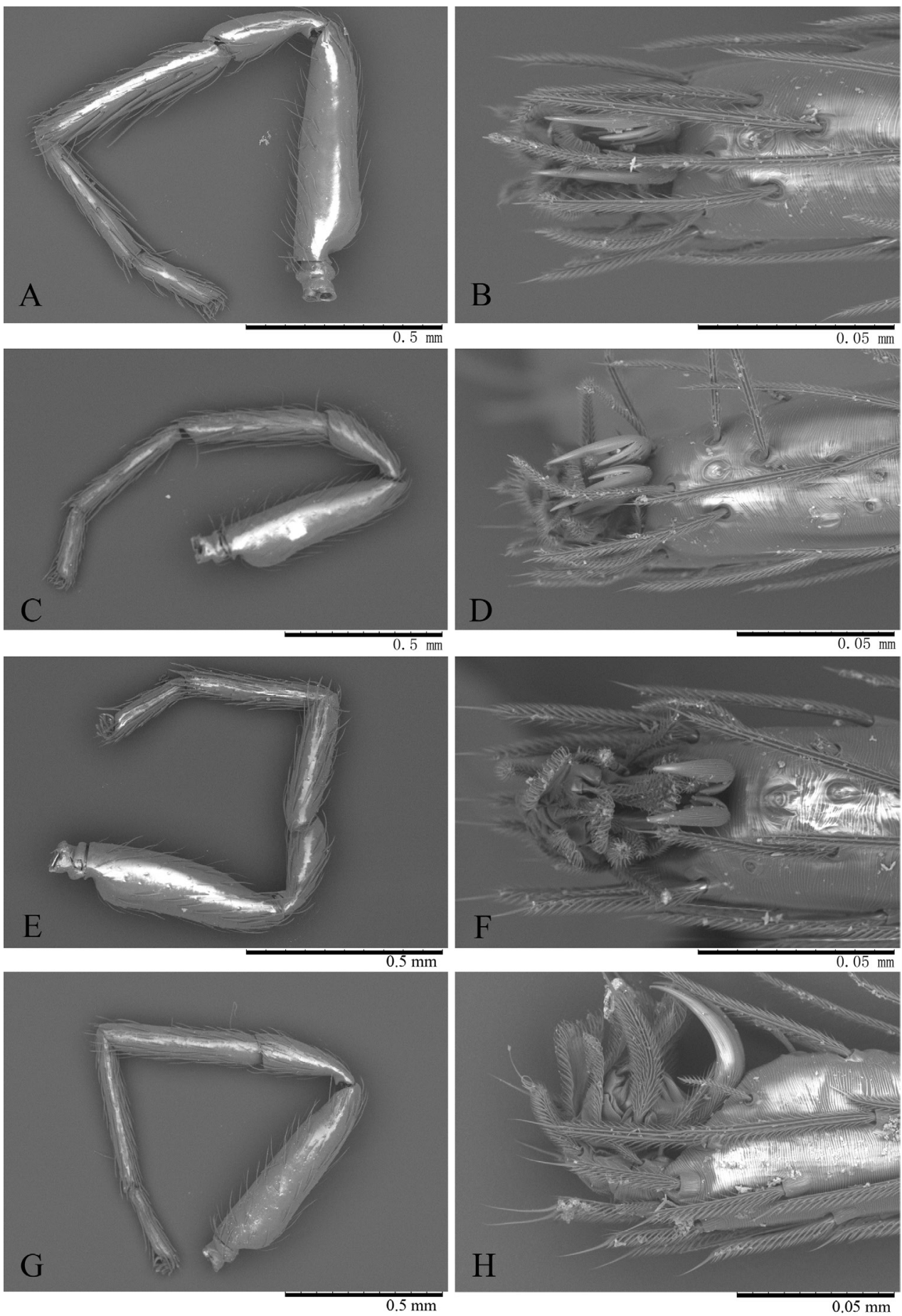

Figure 9. Trilacuna songyuae sp. n., female, right legs, SEM. A leg I, prolateral view B tarsus I, dorsal view $\mathbf{C}$ leg II, prolateral view $\mathbf{D}$ tarsus II, dorsal view $\mathbf{E}$ leg III, prolateral view $\mathbf{F}$ tarsus III, dorsal view G leg IV, prolateral view $\mathbf{H}$ tarsus IV, prolateral view. 


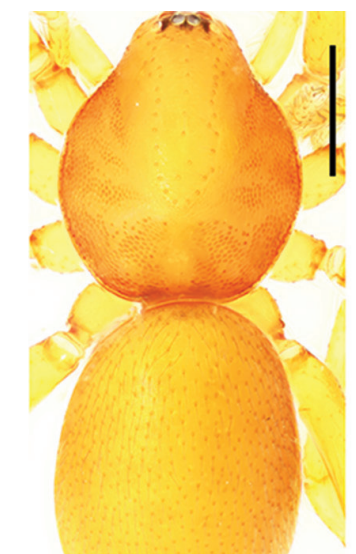

A

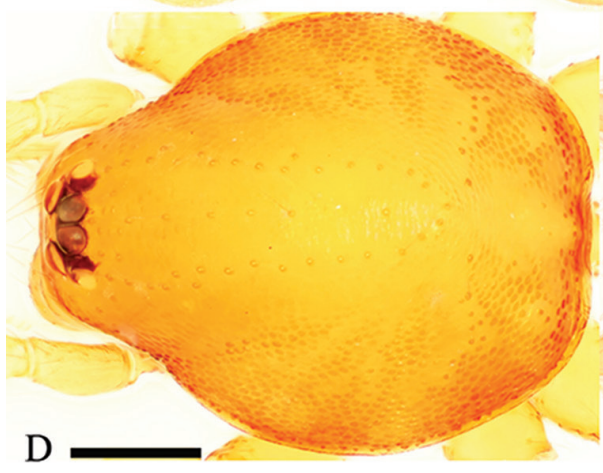

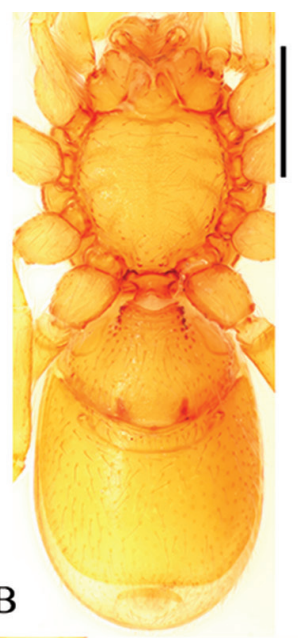

$\mathrm{C}$
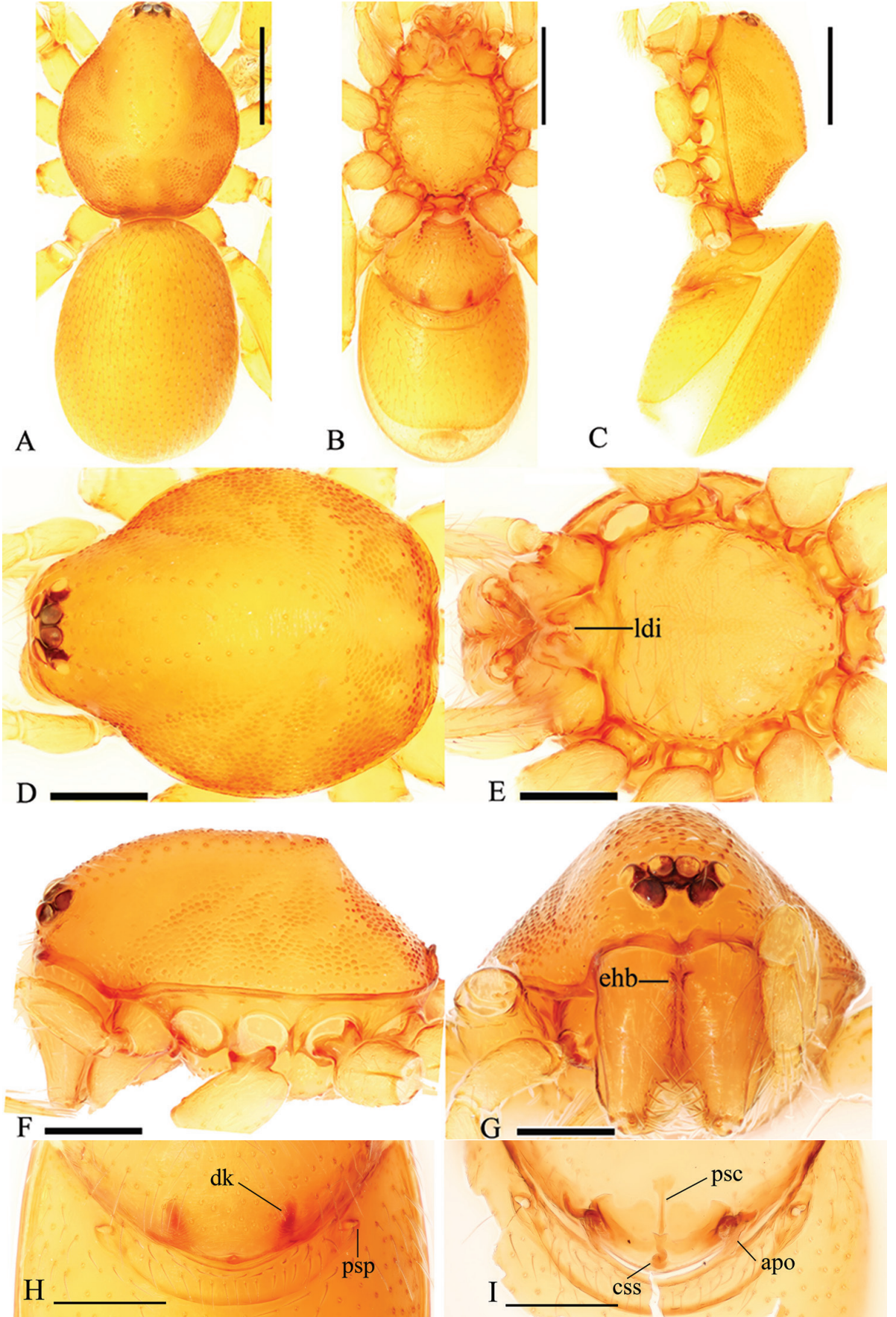

Figure 10. Trilacuna songyuae sp. n., female. A, B, C habitus, dorsal, ventral and lateral views $\mathbf{D}, \mathbf{E}, \mathbf{F}, \mathbf{G}$ prosoma, dorsal, ventral, lateral and anterior views $\mathbf{H}$, I genitalia, ventral and dorsal views. Abbreviations: apo = apodemes; css = cone-shaped structure; $\mathrm{dk}=$ dark knob; ehb = elevated hair base; ldi = labium deep incision; $\mathrm{psc}=$ paddle-like sclerite; $\mathrm{psp}=$ posterior spiracles. Scale bars: $0.2 \mathrm{~mm}(\mathbf{A}-\mathbf{C})$; $0.1 \mathrm{~mm}(\mathbf{D}-\mathbf{l})$. 
parts: chelicerae straight, proximal region with one hair with elevated hair base (ehb); labium rectangular, anterior margin deeply incised (ldi) (Fig. 6E); endites slender, distally slightly branched (sdb) (Fig. 6B). Sternum with radial furrows between coxae I-II, II-III, III-IV; lateral margin smooth, middle area reticulate, posterior part with two slightly elevated ridges, each covered with a row of short, strong setae, the region between the two ridges strongly wrinkled (Fig. 6E). Abdomen: booklung covers (boc) large, ovoid, surface smooth (Fig. 7B). Dorsal scutum not fused to epigastric scutum. Apodemes present, posterior spiracles not connected by groove (Fig. 7A). Leg spination (all spines longer than segment width): legs I-II: tibiae: v2-2-2-2-0, metatarsi: v2-2-0, leg IV: femur with very long hairs ventrally (Fig. 7F). Trichobothria: tibia: each with 3; metatarsus: each with 1 .

Genitalia. Epigastric region (Fig. 7A) with sperm pore small, oval, rebordered, situated before anterior spiracles; with a small dark dot (dd) between the posterior spiracles, a cluster of long hairs around the dark dot. Palp (Figs 7C, D, 8): orange. 0.42 long $(0.14,0.07,0.10,0.11)$. Femur strongly swollen (width/length $=0.08 / 0.14$ ) (Fig. 7C, D). Tibia with numerous, very long, penniform setae (nls) on prolateral surface and two long, strong setae (tss) on retrolateral surface (Fig. 7C, D). Cymbium with two small, spear-like setae (sps) on basal part of prolateral surface (Figs 7C, 8G, H). Bulb long, oval, stout, tapering apically. Embolus system (Fig. 8B, D, F) complex, bearing numerous small "papillae"; with a strongly sclerotized, sickle-shaped protuberance (ssp) and a fan-shaped outgrowth (sso) prolaterally; between the two outgrowths is a cluster of long, line-like structures (cll); with a ribbon-like, nearly transparent outgrowth (rlo) and a broom-like outgrowth (blo) retrolaterally.

Female. As in male except as noted. Slightly larger than male. Body length 1.91; carapace 0.89 long, 0.75 wide; abdomen 1.02 long, 0.78 wide. Postepigastric scutum long. Posterior spiracles connected by groove (Fig. 10B).

Genitalia. Ventral view (Fig. 10H): surface without external features, a dark knob-like marking (dk) can be seen through the cuticle. Dorsal view (Fig. 10I): with a very small, cone-shaped structure (css). Transverse bars with two relatively long, lateral apodemes.

Distribution. China (Chongqing).

\section{Acknowledgements}

The manuscript benefitted greatly from comments by Yuri Marusik, Mark Harvey, Galina N. Azarkina, and Kirill Mikhailov. Sarah Crews kindly checked the language. This study was supported by the National Natural Science Foundation of China (NSFC-31372157, 31572237) and the State Key Laboratory of Forest and Soil Ecology (No. LFSE2015-11) to Yanfeng Tong, by the National Natural Science Foundation of China (NSFC-31530067, 31471960) to Shuqiang Li. 


\section{References}

Eichenberger B, Kranz-Baltensperger Y (2011) New Trilacuna species from Thailand, Malaysia and Sumatra (Araneae, Oonopidae). Zootaxa 2823: 1-31.

Grismado CJ, Deeleman-Reinhold CL, Piacentini LN, Izquierdo MA, Ramírez MJ (2014) Taxonomic review of the goblin spiders of the genus Dysderoides Fage and their Himalayan relatives of the genera Trilacuna Tong and Li and Himalayana, new genus (Araneae, Oonopidae). Bulletin of the American Museum of Natural History 387: 1-108. https:// doi.org/10.5531/sd.sp.1

Malek-Hosseini MJ, Grismado CJ, Sadeghi S, Bakhshi Y (2015) Description of the first cave dwelling species of the spider genus Trilacuna Tong \& Li from Iran (Araneae: Oonopidae). Zootaxa 3972: 549-561. https://doi.org/10.11646/zootaxa.3972.4.6

Seo BK (2017) Four new species of the genera Trilacuna, Orchestina and Hahnia of the families Oonopidae and Hahniidae (Araneae) from Korea. Korean Journal of Environmental Biology 35: 184-190. https://doi.org/10.11626/KJEB.2017.35.2.184

Tong Y, Li S (2007) One new genus and four new species of oonopid spiders from Southwest China (Araneae: Oonopidae). Annales Zoologici, Warszawa 57: 331-340.

Tong Y, Li S (2013) The first goblin spiders of the genus Trilacuna from Vietnam (Araneae, Oonopidae). Zootaxa 3709: 277-284. https://doi.org/10.11646/zootaxa.3709.3.6

Tong Y, Li S (2015) One new genus and two new species of oonopid spiders from Xishuangbanna Rainforest, southwestern China (Araneae, Oonopidae). ZooKeys 494: 1-12. https:// doi.org/10.3897/zookeys.494.9183

World Spider Catalog (2018) World Spider Catalog, version 18.5. Natural History Museum Bern. http://wsc.nmbe.ch [accessed on 26 April 2018] 